\title{
LA FORMACIÓN DEL PROFESORADO DE EDUCACIÓN FÍSICA PARA LA ACTUACIÓN EN LA EDUCACIÓN INFANTIL: DEL PROFESOR REFLEXIVO E INVESTIGADOR
}

Training of Physical Education teachers in early childhood education: about the reflective-teacher and the researcher

Formação de professores de Educação Física na educação infantil: do professorreflexivo e pesquisador

\section{Carmen Lúcia Nunes Vieira}

Doutora em Educação pela Universidade Federal de Santa Catarina/Brasil. Doutoramento sanduíche PDSE/CAPES na Universidad de Valladolid/ES. Professora da Rede Municipal de Ensino de Florianópolis. Núcleo de Estudos e Pesquisas Educação e Sociedade Contemporânea/PPGE/CED/UFSC.

Endereço: Servidão Henrique Thomaz Nunes, 51, Rio Vermelho - Florianópolis/SC. CEP: 88060.315. Correo electrónico: carmenpila@yahoo.com.br.

\section{Cristiano Mezzaroba}

Doutor em Educação pela Universidade Federal de Santa Catarina/Brasil. Professor do Departamento de Educação Física da Universidade Federal de Sergipe. Pesquisador LaboMídia UFS. Grupo Corpo e Política/UFS. Núcleo de Estudos e Pesquisas Educação e Sociedade Contemporânea/PPGE/CED/UFSC.

Endereço: Rua Capitão Américo, 103 - Bloco B, apto 406 - Córrego Grande Florianópolis/SC.CEP: 88037-060. Email: cristiano_mezzaroba@yahoo.com.br.

\section{Resumen}

Nuestra intención en este artículo es reflexionar sobre la formación del profesorado de Educación Física que actuará en centros de educación infantil. Para eso dialogamos con las concepciones del profesional reflexivo (Schon) y el profesor como investigador (Stenhouse) en la formación del profesorado. Nos damos cuenta que Schon y Stenhouse consideran el protagonismo de los profesionales de la educación, pero llamamos la atención para no sobrecargarlos con demasiadas responsabilidades que extrapolan sus prácticas. Los dos conceptos señalan posibilidades para nuevas metodologías 
aproximando teoría y prácticas y profundizan la actuación profesional por las potencialidades y desafíos que presenta la contemporaneidad.

Palabras Claves: formación del profesorado, educación fisica, educación infantil.

\begin{abstract}
His text aims at reflecting on the formation of the Physical Education teachers who are interested in acting professionally in the Early Childhood Education field. Thus, a dialogue with the conceptions of the reflective-teacher (Schon) and researcher-teacher (Stenhouse) is established. It is possible to assess that Schon and Stenhouse consider the prominence of education professionals, but we caution against overloading them with responsibilities that go beyond their area of performance, mainly the Physical Education teacher who works with Early Childhood Education, when it comes to training or teaching, both the concepts are posed as possibilities for new methodologies, approaching theory and practice. Such understandings can amplify the action of the pedagogical work, for the potentialities and challenges that contemporaneity presents us with.
\end{abstract}

Keywords: teacher training, physical education, early childhood education.

\title{
Resumo
}

Nosso intuito neste texto é refletir sobre a formação do professor de Educação Física, que tem interesse em atuar profissionalmente na Educação Infantil. Para tanto dialogamos com as concepções do professor-reflexivo (Schon) e professor-pesquisador (Stenhouse) na formação de professores. Avaliamos que Schon e Stenhouse consideram o protagonismo dos profissionais da educação, porém alertamos para o cuidado de não sobrecarregá-los com responsabilidades que extrapolem sua atuação. Especificamente ao professor de Educação Física na Educação Infantil, quer na formação ou atuação, ambas as concepções colocam-se como possibilidades para novas metodologias, aproximando teoria e prática. Tais entendimentos podem ampliar a ação do trabalho pedagógico, pelas potencialidades e desafios que a contemporaneidade nos apresenta.

Palavras-chaves: formação de professores, educação fisica, educação infantil. 


\section{Nota introdutória}

A discussão em torno da formação profissional ganha cada vez mais ares técnicos e científicos, até porque, sabemos, vivemos numa época em que a ciência ocupa um importante espaço social. Em relação à formação docente, isso também ocorre, com suas particularidades, tensões e com intencionalidades diversas, em que o foco, de uma forma ou de outra, sempre se coloca na qualidade da formação desses futuros professores e com isso, numa melhora da educação em seus vários níveis de ensino, desde a educação infantil, passando pelo ensino fundamental e médio, culminando com o ensino superior.

Quando nos referimos à formação de professores no Brasil, qualquer análise reflexiva deve levar em consideração o contexto da universidade, lócus da formação profissional, em especial a universidade pública. Chaú $(2003$, p.5) considera que a universidade "exprime de maneira determinada a estrutura e o modo de funcionamento da sociedade como um todo." Assim, não podemos considerar que a universidade esteja isolada ou "descolada" da sociedade em sua integralidade, o que mostra que sua autonomia - quando pensada em relação aos profissionais e em particular aos professores que forma - não é absoluta, e sim relativa.

Conforme Chaú (2003), a ideia de formação implica duas questões gerais principais: uma delas seria a ação com o tempo, em que o sujeito seria introduzido ao passado de sua cultura; a outra, é quando há obra de pensamento, com interrogação, crítica e reflexão. Já para Charlot (2005: 90), "Formar alguém é torná-lo capaz de executar práticas pertinentes a uma dada situação, definida de maneira restrita (função no trabalho) ou ampla (em referência a um setor de trabalho encarregado de um processo de produção)." Para este último autor, formar professores seria o trabalho com saberes e práticas, ou, em suas palavras, a prática do saber e os saberes da prática, essa constante tensão - ou mediação - entre o abstrato e o concreto.

Percebemos pelas passagens citadas o que sempre, inevitavelmente, fica no debate quando tratamos de educação: a relação teoria e prática. É essa tensão que acaba gerando constantes embates quando pensamos o campo da formação de professores e a atuação profissional. Ora um polo é valorizado, ora o outro passa a ter destaque nos discursos e documentos oficiais quando se trata dessa formação, como podemos constatar na obra sistematizada por Contreras (2012). 
A questão da formação de professores intriga grande parte de pedagogos, mas também filósofos, sociólogos, psicólogos, antropólogos, e nos últimos anos, até economistas se preocupam com tal problemática. Seja no Brasil ou no mundo, há um campo de debates profícuo que, ao menos no plano acadêmico-científico, está em constante troca de ideias, propostas e concepções.

No Brasil e em um campo profissional mais específico, no caso a Educação Física (EF), tais discussões são constantes e complexas, principalmente pela recente especificidade dos cursos de licenciatura, qual seja, preprarar o futuro professor exclusivamente para atuar no âmbito escolar, e em grande maioria com a infância. Outra peculiaridade está na relação teoria-prática, pela forte identificação dos professores de EF com as práticas corporais - hegemonicamente esportivas - em detrimento aos aspectos teóricos do conhecimento, sobretudo aos que dizem respeito à infância e suas especificidades, desde a formação inicial às práticas pedagógicas ${ }^{1}$.

Diante disso, neste texto nosso objetivo é refletir sobre a formação de professores, em especial ao que se refere à formação em EF e, particularmente, no que alude à atuação na Educação Infantil (EI), em diálogo tensionado com as possibilidades relacionadas ao professor-reflexivo (Schon) e ao professor-pesquisador (Stenhouse). Isso porque, tais concepções, já bastante discutidas no campo da pedagogia, podem permitir à formação de professores de EF, e aos que têm como enfoque docente, a infância, ampliar possibilidades teórico-práticas na direção de um trabalho pedagógico atualizado, crítico, reflexivo e embasado cientificamente, em diálogo com a contemporaneidade e suas potencialidades e desafios.

Organizamos nossas reflexões da seguinte maneira: ao tomarmos como objeto o contexto da formação de professores no Brasil, dialogamos e refletimos sobre os termos-chaves elencados - professor-reflexivo e professor-pesquisador - realizando as análises a partir de Contreras (2012) e dialogando com demais autores/as, articulados

\footnotetext{
${ }^{1}$ Vieira e Welsch (2007: 129-140), em investigações sobre a formação inicial em EF e a atuação de professores de EF em instituições de Educação Infantil, na cidade de Florianópolis/SC/Brasil, dizem que mesmo com "inserções de disciplinas de cunho pedagógico e mudanças de currículo, perpetua-se a indicação de uma formação acadêmica, ainda, generalista e esportivizada", carecendo discussões sobre temas ligados à Infância e à EI em articulação com a EF. Estas, quando presentes, aparecem de forma reducionista, atrelando-se às abordagens desenvolvimentistas - por exemplo, disciplinas de desenvolvimento motor e aprendizagem motora. E, mais, que por conta dessas limitações na formação os professores acabam por basear suas práticas em conhecimentos de cunho técnico permeados pelo senso comum, proveniente de suas experiências, quase sempre, exteriores às formações acadêmicas e vinculadas ao saber fazer, melhor dizendo, a biografia esportiva de cada um.
} 
com a formação do professor de $\mathrm{EF}$, principalmente àqueles que vislumbram atuar profissionalmente com a infância, e em especial, em centros de EI.

\section{A formação de professores: do professor-reflexivo e professor-pesquisador}

Há inúmeras formas de pensar atualizações e proposições para uma formação que considere, além dos aspectos técnicos, questões mais amplas em torno da formação de professores, especialmente de EF. Pautados em Contreras (2012), apresentaremos duas delas e uma possível articulação entre ambas: a concepção de professor-reflexivo, proposta por Donald Schön e a de professor-pesquisador, de Lawrence Stenhouse.

Contreras (2012), em $O$ docente como profissional reflexivo, trata de maneira crítica, para além da mera apresentação, a concepção do professor reflexivo, articulando uma discussão prévia sobre o professor como pesquisador, conforme proposto por Stenhouse. A perspectiva do profissional reflexivo surge em oposição/crítica ao modelo de racionalidade técnica como concepção de atuação profissional, a qual revela sua incapacidade para tratar e resolver o que é imprescindível, o que não pode ser interpretado como raciocínio infalível. Para tal autor é a perspectiva positivista que provoca essa incapacidade e desconsidera imprevistos, incertezas, dilemas e situações de conflito, carecendo das habilidades humanas relacionadas com a capacidade de deliberação, reflexão e consciência.

Nesse contexto, emerge no debate, a partir de Donald Schön, a ideia de professor reflexivo, que aborda a forma como os professores enfrentam situações incertas, instáveis, singulares, que não se resolvem pelos repertórios técnicos. Para Schön, as atividades espontâneas do cotidiano podem ser realizadas de duas formas: conhecimento na ação e reflexão na ação. O conhecimento na ação seria o conhecimento do cotidiano, não sistematizado, tácito, implícito, espontâneo, naturalizado, interiorizado, um conhecimento que não precede a ação. Já a reflexão na ação se caracteriza como a reflexão realizada enquanto estamos fazendo algo, ou seja, analisar em relação à situação que nos encontramos, envolvendo a repetição. Segundo Schön, o processo de reflexão na ação transforma o profissional em um pesquisador no contexto da prática - visualiza-se aqui uma forte aproximação com o proposto por Stenhouse, de professor-pesquisador. O professor não depende de teorias e técnicas preestabelecidas: ele cria uma nova maneira de ver o problema. 
Analisando tal concepção, Contreras (2012: 122) escreve que: "A prática constitui-se, desse modo, um processo que se abre não só para a resolução de problemas de acordo com determinados fins, mas à reflexão sobre quais devem ser os fins, qual o seu significado concreto em situações complexas conflituosa.”. E que "[...] os processos de reflexão acabam sendo fonte de novos conflitos e discussões em torno dos limites que, para a compreensão e ação, as instituições e as práticas sociais colocam em relação aos problemas profissionais." (Contreras, 2012: 122).

Ainda sobre o professor reflexivo, Contreras (2012) comenta que seria uma formação que envolveria uma dupla necessidade, qual seja, primeiramente, entender e interpretar a situação (já que ela é inédita), para, em seguida, modificá-la, elaborando novas atuações como produto de uma nova interpretação. Seria, numa linguagem metafórica, assim considerada por Schön, uma prática profissional como situação artística, em que se recuperaria a reflexão como prática, que embora racional não é algo técnico. Além disso, a atuação do professor reflexivo seria semelhante ao seguido pelos pesquisadores em suas experimentações - o que gera uma crítica de Contreras: situações pedagógicas também são situações controláveis de laboratório? Propomos que a ideia de "laboratório" aqui colocada, em relação à pesquisa e às investigações, pode ser alargada para além da representação trivial que temos de ciência numa perspectiva biológica, física, natural, e sim uma ciência que considere os aspectos humanos, especialmente sociais e culturais.

Visualizamos uma aproximação com a proposta do professor-pesquisador (Stenhouse), já que o professor não depende de teorias e técnicas preestabelecidas: ele cria uma nova maneira de ver o problema. Também para Contreras (2012) há semelhanças entre Schön e Stenhouse. Para o último, o ensino é uma arte, que significa a expressão de certos valores, em que a busca se realiza na própria prática de ensino: os docentes seriam como artistas que melhoram sua arte. E assim inaugura a concepção do professor como pesquisador, para a qual é importante considerar as singularidades das situações educativas (Contreras, 2012: 128). O que importa na educação é atender às circunstâncias que cada caso apresenta, sem pretender a uniformização dos processos educativos. O professor pesquisador de sua própria prática a transforma em objeto de investigação, buscando aprimorá-la. Como o currículo é a expressão da prática, é ele o elemento de reconstrução para que haja reconstrução da ação do professor. (Contreras, 2012: 132). Poderíamos dizer que para Stenhouse há ênfase no "processo" e não no 
"produto" da educação: "[...] os valores educativos representam aspirações e não conquistas" (Contreras, 2012: 129).

Contreras (2012), ao abordar sobre $O$ fundamento aristotélico: a racionalidade prática, considera que tanto Schön como Stenhouse trabalham a partir da racionalidade prática aristotélica (Idem, p.137). Para Aristóteles há uma diferença clara entre o que se chama de atividades técnicas e atividades práticas. As técnicas se dirigem à produção para se obter como resultado coisas que são diferentes dele própria. As práticas se dirigem a realizar na própria ação os valores que se consideram corretos para ela. Segundo a ética aristotélica, a educação é um tipo de atividade prática quando é dirigida para a realização de qualidades intrínsecas ao próprio processo educativo.

[...] a prática pedagógica, ante os momentos que apresentam características de surpresa ou de incerteza, exigem deliberação, reflexão e pesquisa com o objetivo de arbitrar o melhor modo de proceder no caso, isso sempre em relação aos significados que os valores educativos pretendidos devem adquirir nas circunstâncias particulares. (Contreras, 2012: 139).

Há um ponto de discordância que podemos nos atentar entre as concepções de Schön e de Stenhouse. Enquanto, para o primeiro são os casos práticos e suas dificuldades ou as surpresas que orientam a reflexão gerando situações problemáticas, para o segundo, deve-se "provocar" situações práticas de problemas que são o motor da reflexão, gerando experimentações práticas.

De que maneira, então, podemos tecer prováveis tensões e possibilidades do professor-pesquisador e do professor-reflexivo em articulação com a formação de professores de EF, em particular os que vislumbram atuar na Educação Infantil? A partir de agora, dedicamo-nos a pensar associações, imbricações e debates possíveis, considerando a tensão entre o que pode ser proposto e as limitações que podem ser encontradas.

4. Professor-reflexivo e professor-pesquisador e a formação de professor de EF: diálogos, articulações e a atuação na Educação Infantil 
Muito tem se afirmado, discursado, proposto e investigado em relação à formação de professores de EF e suas diversidades - tanto curriculares, como pedagógicas e práticas - considerando-se o contexto brasileiro e sua contemporaneidade. Uma das questões que mais são reiteradas é a necessidadede de pesquisa empírica na escola, tanto por pesquisadores universitários, como por professores de EF, os quais devem passar a se verem, também, como pesquisadores da sua própria realidade - efetivando-se, com isso, os pressupostos do professor reflexivo.

Rodrigues (1998: 55), baseada em Schön, aponta a necessidade de, na formação em EF, tratar da reflexão como componente complexo e importante na atividade do professor. Em relação ao professor de EF, "Sua atuação deve ser de intelectual crítico, autônomo e criativo, que se preocupa em tornar o conhecimento de que trata a Educação Física (cultura corporal) mais significativo e emancipador”.

Tal dimensão permitirá que os futuros professores, formados a partir das reais demandas da nossa complexa e diversa sociedade contemporânea, atuem sem perder de vista sua condição de pesquisadores de seu próprio campo pedagógico, com um olhar mais afinado e atento àquilo que acontece em seus cotidianos, no que se refere aos conteúdos, às questões teórico-metodológicas e às problemáticas enfrentadas no dia-adia. A reflexão sobre as práticas e diálogos entre professores e pesquisadores, novamente, permitirão compartilhar visões distintas em prol da produção de conhecimento na/da EF.

Nesse contexto, as aproximações com a Antropologia poderão ser imprescindíveis, tanto pela necessidade de ampliar o "olhar", bem como ao fato de “ouvir" e, depois, "escrever" sobre os objetos, sujeitos, práticas - enfim, o campo investigados.

Para isso, mais do que nunca, será preciso seguir as recomendações de Oliveira (2000), sobre o que, para ele, parecem ser as etapas mais estratégicas na produção do conhecimento antropológico: o olhar, o ouvir e o escrever como constantes do processo do fazer antropológico por meio da observação participante. Para este antropólogo, a 
função de escrever o texto, além de ser uma tentativa de exposição de um saber é também uma forma de se produzir conhecimento ${ }^{2}$.

Segundo Oliveira (2000), o olhar talvez seja a primeira experiência do pesquisador de campo e daí a necessidade de domesticá-lo teoricamente, considerando que o objeto empírico a ser pesquisado já se modifica simplesmente quando decidimos estudá-lo, ou seja, passamos a vê-lo, desde já, de forma diferente. O mesmo escreve que:

[...] a partir do momento em que nos sentimos preparados para a investigação empírica, o objeto, sobre o qual dirigimos nosso olhar, já foi previamente alterado pelo próprio modo de visualizá-lo. Seja qual for esse objeto, ele não escapa de ser apreendido pelo esquema conceitual da disciplina formadora de nossa maneira de ver a realidade. (Oliveira, 2000: 19)

Mas não cabe apenas o exercício isolado do "olhar". Este deve ser complementado com o exercício de "ouvir" e de "escrever" também. O ouvir, assim como o olhar, tem uma significação específica para um cientista social e não podem ser tomados como propriedades totalmente independentes no exercício da investigação, pois ambas completam-se e servem para o pesquisador "como duas muletas [...] que lhe permitem caminhar, ainda que tropegamente, na estrada do conhecimento." (Oliveira, 2000: 21).

Ao situarmos a EF e a formação de professores em sua historicidade constata-se

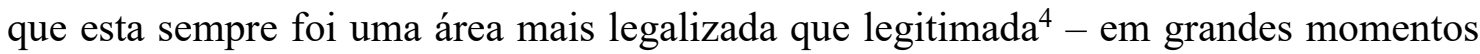
questões importantes foram colocadas via portarias, decretos e leis, ao invés de se legitimarem perante a sociedade - sendo vista como algo eminentemente "prático". São bons exemplos os decretos 5540/68 e 5692/71 e Parecer 853/CFE/71, os quais atribuíam à EF caráter de "atividade" (Pinto, 2002). Mudança, ao menos no plano normativo, só ocorreu com a Lei de Diretrizes e Bases (LDB 9394/96), que considerou

2 Para Oliveira (2000), o olhar, o ouvir e o escrever constituem formas as quais nos permitem conhecer especificidades daquilo que se estuda nas ciências sociais (ou as "teorias sociais" - denominação atribuída à Anthony Giddens).

${ }^{3}$ No ato de escrever, segundo Oliveira (2000), é que se configura o produto final do trabalho de campo (também chamado de fieldwork), momento em que a questão do conhecimento torna-se tanto ou mais crítica.

${ }^{4}$ Bracht (1997) afirma que é tarefa nossa, enquanto professores de EF, desenvolver um corpo teórico da $\mathrm{EF}$, já que somos os sujeitos que constituímos tal área. E para isso é necessária investigação pedagógica diferente da que se fez e se vem fazendo na EF brasileira. 
a EF "componente curricular", quer dizer, algo que era apenas "prático" passa a ser "conhecimento", e, consequentemente, a exigência de que seja trabalhado pedagogicamente.

Como área de conhecimento, há inúmeras possibilidades quanto à reflexão que adentra o ról de saberes, práticas, elementos de investigação, para dar continuidade àquilo já produzido e tratado pedagogicamente via mediações educativas pela EF escolar. Entretanto, é necessário considerar que pesquisar, no âmbito da EF, conforme nos alerta Vaz (1994), demanda o hábito do rigor, a fim de que toda e qualquer investigação que se pretenda útil, seja, em primeira instância, veículo de transformação social, legitimando um campo do saber e seus sujeitos, agentes produtores do conhecimento que, com o passar do tempo, vão garantindo, também, a legitimação de seu lócus científico, a partir da qualidade do que é produzido e socializado. Pesquisar, assim, é tornar claro o contexto histórico, teórico, político, filosófico e epistemológico de onde surge a investigação, seu processo e suas implicações. Tarefa, portanto, que pressupõe compromisso, comprometimento, responsabilidades e, acima de tudo, ética.

Pensar a perspectiva do professor enquanto profissional reflexivo e pesquisador se alia ao que Demo (2003) aborda em relação ao princípio do educar pela pesquisa, em que o pesquisador deve desenvolver sua pesquisa com princípios científicos e educativos, como atitude cotidiana. Considerando seu repertório das experiências anteriores, valores, sentidos e significados, intenções, racionalidades e subjetividades que marcam as intencionalidades, tensões e as escolhas quando se pretende investigar um determinado fenômeno.

Essa mesma perspectiva é encontrada em Meksenas (2002: 16):

Aos profissionais do ensino já não basta transmitir conteúdos por meio das relações de ensino e aprendizagem. Mais e mais é importante que professores, pedagogos e administradores da educação assumam o papel de construtores do conhecimento. Para tanto, é fundamental não dissociar o ensino da pesquisa, percebendo na interação dessas duas atividades o complemento que torna a educação possível. 
$\mathrm{Na}$ mesma direção, abordando mais especificamente a formação em EF e a atuação docente, incluso em ambientes que atendam a pequena infância, Vaz (2008: 7980) menciona:

Todo aquele que atuará profissionalmente no ensino e na orientação de práticas corporais escolares, no lazer, nos esportes, na "promoção da saúde", entre outras possibilidades, deve ter a experiência da pesquisa em sua formação para que possa empregar suas estratégias sistematicamente em seu trabalho profissional. Não é preciso tornar-se pesquisador, mas é importante ter a dimensão da pesquisa na formação para que a atividade profissional não seja mera repetição de fórmulas. [grifos nossos].

Portanto, ponderamos ser possível uma articulação da formação de professores de EF com as concepções de professor-reflexivo e professor-pesquisador, pensadas, também, no âmbito da atuação na Educação Infantil. Partindo da premisa que o professor não é mero reprodutor, mas, e principalmente, pesquisador de sua própria prática, tentamos apresentar problematizações e reflexões tendo como foco temas pertinentes à infância, como as brincadeiras e os jogos, as questões relacionadas ao corpo e as práticas corporais.

Marcel Mauss (1974), antropólogo francês, certamente poderá ser de grande ajuda àqueles que se lançarem nesta tarefa de pesquisar e refletir sobre sua própria prática em relação a um trabalho com crianças, a partir daquilo que ele denominou de técncias corporais. A partir da leitura de seus escritos, entendemos que o processo de educação do corpo, que começa desde muito cedo, e talvez por isso vai se naturalizando em nós, mostra que se olharmos atentamente para este processo perceberemos traços de um objetivo mais geral: através das mais variadas técnicas, corporalmente vamos incorporando valores, gestos e padrões que são gerais em nossa sociedade e são próprias de nossa cultura: a nossa fala, o nosso andar, o nosso "gosto" por isso ou por aquilo, o nosso comportamento, entre tantas outras coisas.

Mauss (1974), ao tratar as técnicas corporais, está pensando na dimensão da mudança histórica que ocorre também em relação ao corpo. Para ele, é difícil pensar a existência humana sem pensar na cultura e na sociedade, pois não existe um ente 
natural (ideia de criador e criatura). Ele entende que a expressão técnicas corporais ${ }^{5}$ seriam "as maneiras pelas quais os homens, de sociedade a sociedade, de uma forma tradicional, sabem servir-se de seu corpo.” (Mauss, 1974: 401)

Outra contribuição de Mauss àqueles que se lançarem a essa aventura investigativa e reflexiva refere-se ao movimento de partir "do concreto em direção ao abstrato", ou seja, a partir daquilo que se apresenta no cotidiano, materialmente, como “educação do corpo", abstrair em direção a construção de conceitos, de didáticas, de problemáticas a partir da prática.

Mauss (1974) acredita no processo de educação quando se refere às técnicas corporais, isto é, "O ato se impõe de fora, do alto, mesmo um ato exclusivamente biológico, relativo ao corpo. O indivíduo assimila a série dos movimentos de que é composto o ato executado diante dele ou com ele pelos outros." (Mauss, 1974: 405). Ocorre que a criança, em contato com o adulto, acaba imitando-o devido, principalmente, ao prestígio do adulto em relação a elas. $\mathrm{O}$ ato imitador seria a forma de se "visualizar" o aspecto social nessa noção de prestígio, e nele mesmo, pode-se verificar, também, o elemento psicológico e o elemento biológico.

Nos ambientes educacionais há a preocupação de transmitir às crianças noções das mais variadas, mas a principal dela seria a perpetuação de uma tradição, de acordo com os valores e princípios mais gerais de cada sociedade. Segundo Mauss (1974: 407), "Não há técnica e não há transmissão se não houver tradição. Eis em quê o homem se distingue antes de tudo dos animais: pela transmissão de suas técnicas e muito provavelmente por sua transmissão oral".

Um exemplo dessa relação entre o observado em contextos educacionais infantis e as "técnicas corporais" refere-se à publicação de Richter e Vaz (2005), os quais realizaram uma investigação etnográfica em um ambiente educacional de 0 a 6 anos da rede pública de ensino de Florianópolis e, assim, elaboraram uma agenda de estudos sobre a educação do corpo na infância, sistematizando algumas categorias que

\footnotetext{
${ }^{5}$ Em seu clássico texto, Mauss exemplifica das mais variadas formas como ocorreria este processo no decorrer dos tempos, como por exemplo, as diferenças na forma de aprendizagem do mergulho, a forma de cavar e de marchar diferenciada das tropas inglesa e francesa, o andar das jovens francesas em comparação às norte-americanas (as primeiras sendo influenciadas pelas últimas graças ao cinema americano que chegava à França), entre tantos outros exemplos que aparecem no texto.
} 
permitiriam pensar em tais elementos, como por exemplo, corpo-higiene, corpoalimentação $^{7}$, corpo-sono $^{8}$, corpo-parque ${ }^{9}$, corpo-atividade orientada ${ }^{10}$.

Acordamos com Silva e Pires (2007) quando dizem saber que "a problemática da EF na Educação Infantil é um tema pouco explorado na bibliografia brasileira da área", com algumas publicações esporádicas, mesmo que o tema infância, enquanto "categoria ontológico-social", venha ganhando certo destaque na produção do conhecimento em EF, implícita ou explicitamente. Mas faltam mais produções que contemplem as políticas públicas para a EF na Educação Infantil, "considerando o vasto universo de problemas que envolvem não só as questões polêmicas, de viés ontológico, epistemológico, mas, em especial, político-pedagógico". (Silva e Pires, 2007: 08).

Por isso no que tange a EF na Educação Infantil, ainda temos muito que investigar, e aprofundar temas imbricados com a formação e atuação com crianças pequenas, tais como infância e criança, brincadeira e jogo, tempo/espaço na instituição infantil, lúdico, conteúdos/saberes, relações adulto/criança, entre outros. Porém,

Isto implica questionar profundamente a concepção racionalista que, historicamente, permeia tanto as práticas educacionais quanto a formação docente, pois a produção dos sujeitos humanos tem sido um constante inculcamento da disciplinarização de seus próprios corpos. (Sayão, 2002: 58).

A autora continua dizendo, devido suas investigações com os envolvidos com a docência na pequena infância, que existem falhas, "faltas" e "incapacidades":

\footnotetext{
${ }^{6}$ Referem-se aos aspectos relacionados à saúde e à higiene quando o que se pretende, em relação aos diálogos e práticas com as crianças, constituir sujeitos higiênicos, purificados e moralizados, sendo necessários momentos de eliminação de sujidade. (Richter e Vaz, 2005)

${ }^{7}$ Categoria oriunda da observação das práticas dos professores quanto à alimentação das crianças. Compreende-se desde os gestos rápidos das professoras ao servir, recolher, limpar, cortar, distribuir alimentos e, ao mesmo tempo, ingerir algum. Da maneira como é realizada essa alimentação, os odores, sabores, cores, texturas, prazeres e desprazeres se perdem em meio à administração maquinal de organismos que são abastecidos nessa pseudo-atividade que meramente garante a autoconservação física e, ao mesmo tempo, ensina a, tecnicamente, sujeitar-se. (Richter e Vaz, 2005)

8 Os momentos de sono e de repouso são caracterizados por meio da categoria corpo-sono. Nestes momentos o que se percebe é a desconsideração de alguns elementos de sono, como por exemplo, a individualidade das crianças e suas preferências (tempo de duração do sono, vontade ou não de dormir, questões de iluminação do ambiente, de preferências espaciais e de distribuição em meio aos seus colegas, entre outros). (Richter e Vaz, 2005)

${ }^{9}$ São vistos como momentos em que as crianças se soltam e que elas ficam mais livres. Geralmente as professoras apenas observam as crianças, deixando tudo correr à solta, sem mediação pedagógica. (Richter e Vaz, 2005)

${ }^{10}$ Observação em que se percebe certa regulação corporal das professoras para com as crianças, com destaque para os castigos e às ameaças lançadas sobre o corpo. (Richter e Vaz, 2005)
} 
A escuta das futuras pedagogas dos/as acadêmicos/as da educação física, assim como de profissionais já atuantes no magistério, demonstra as "faltas" decorrentes de seu processo de formação que se evidenciam numa certa "incapacidade" momentânea de perceberem a brincadeira, o jogo e o movimento corporal das crianças para além do aspecto funcional de contribuição para a melhoria das aprendizagens cognitivas o dos esportes de rendimento. (Sayão, 2002: 58).

Portanto não só o tema infância em si, mas, e, também a maneira como adultos e crianças se relacionam com as práticas corporais, as brincadeiras e jogos, devem ser aspectos compreendidos para além da dimensão prática e funcional. Isso é possível por um processo de reflexão, quando nos referimos à atuação docente de "reflexão na ação", ou seja, no contexto de sua prática, o que nos aproxima do pretendido por Schön e seu professor-reflexivo e Stenhouse e o professor-pesquisador.

Também não podemos desconsiderar que historicamente a área de EF esteve vinculada a duas principais temáticas, a saúde e o esporte, enfim, com os "cuidados com o corpo", aos seus saberes e fazeres, e essa tradição não poderia ficar de fora na abordagem com crianças. Obviamente que o trabalho pedagógico em relação a essas duas temáticas deve ser adaptado às reais condições e características deste público escolar, entretanto, é inevitável que aí, novamente, a EF tem um rico campo de práticas investigativas e reflexivas em suas ações.

Outra perspectiva que dialoga plenamente às questões do professor-reflexivo e do professor-pesquisador está associada às questões midiáticas e tecnológicas e sua penetração no cotidiano das crianças pequenas, e as possíveis implicações disso em suas corporeidades/práticas corporais, dialogando com autores/as que vêm trazendo essas discussões do campo educacional com as tecnologias/mídias, como Ferrés (1996), Belloni (2001) e Fantin (2006).

Aos professores de EF, além dos saberes advindos de suas experiências, formação inicial e pós-graduação, soma-se uma infinidade de conteúdos oriundos de noticiários, transmissões esportivas, programas de televisão e revistas "especializadas" nas temáticas da qualidade de vida e saúde, emagrecimento e beleza etc. 
Os exemplos apresentados podem ser pautados pelo viés sociológico, das humanidades, na tentativa de analisar algumas problemáticas, que inicialmente parecem se colocar como exclusivadade da EF, mas estão articuladas com outros saberes. As questões de consumo e mercadorização (como a relação entre jogos e brincadeiras das crianças influenciadas pela lógica da indústria cultural, em especial, desenhos animados e suas publicidades endereçadas a esse público segmentado), os jogos eletrônicos (suas possibilidades e limites), as problemáticas de gênero, etnia, corpo, estética, meio ambiente, valores, entre tantos outros, configuram-se como situações que compactuam com o proposto por Schön e Stenhouse quanto ao professor enquanto profissional reflexivo e enquanto pesquisador.

\section{Considerações finais}

Apesar das críticas coerentes que existem tanto em relação à concepção do professor-reflexivo quanto a do professor-pesquisador como possibilidades de ampliação do repertório e de uma melhor qualidade na formação dos professores de um modo geral, pensando nas implicações disso no dia a dia escolar, nas práticas e mediações pedagógicas, é possível fazer-se uso de tais concepções se se pretende novas práticas de formação. Obviamente, essas "novas práticas" não devem hierarquizar a prática sobre a teoria, tendo em vista que apesar de serem coisas distintas, teoria e prática devem caminhar juntas quando se fala em "formar" alguém que atuará na formação de uma nova geração.

Algumas questões não são muito claras quando Schön apresenta seu modelo de professor que investiga e reflete sobre sua própria prática, muitas vezes parece que há uma hierarquia entre o pesquisador científico e o pesquisador escolar. Obviamente, que àquele que participa da esfera acadêmica, a pesquisa tem funções mais epistemológicas, ainda mais quando nos referimos ao campo da pedagogia em associação às ciências humanas e sociais, enquanto que ao professor que atua na escola suas demandas são mais cotidianas, relacionadas a questões mais presentes na relação com o conteúdo trabalhado e com sua realidade escolar.

Contreras (2012: 121), ao tratar de Schön, comenta que para este, a partir da reflexão na ação, enquanto sujeito que investiga no contexto da prática, se "constrói uma nova maneira de observar o problema". Podemos inferir que há nisso uma certa 
ênfase nas questões práticas. A prática, isoladamente, não dará conta de colocar e responder aos problemas daqueles que atuam e pesquisam no ambiente escolar. Não será possível avançar numa formação mais sólida, atualizada, crítica, reflexiva e autônoma - palavras e adjetivos comumente relacionados à formação de professores na atualidade - se apenas colocarmos como "ordem do dia" uma formação construída pelas/para as questões práticas.

Uma formação de professores que considere a ampliação de repertório, tanto do ponto de vista teórico, metodológico, prático e epistemológico, mas também político e cultural, é possível quando se associa a isso os referenciais de uma formação que leve em conta a figura do "pesquisador", como aquela que exige de novos profissionais um olhar apurado sobre seu mundo social, sobre seus sujeitos, suas possibilidades, perspectivas e expectativas. Retirando dos currículos universitários aqueles elementos teóricos e científicos, paradoxalmente, não permitirá uma formação assim, como tanto se almeja em discursos acadêmico-científicos e políticos também.

Dialogando com Contreras (2012: 131), ao considerar que a partir da visão de Stenhouse sobre currículo, o qual acredita que as ideias educativas "só chegam à aula em forma de especificações curriculares e só podem ser comprovadas pelos professores por meio do currículo", podemos pensar que Stenhouse desconsidera o poder simbólico e "prático" do currículo oculto, que a todo instante, no meio escolar, coloca-se como algo que deve ser observado, tendo em vista seu poder diante das questões curriculares, como aquilo que "foge" das formalidades, dos currículos e da própria cientificidade, tão importantes à formação humana e profissional.

Por fim, não há dúvidas que tanto Schön como Stenhouse consideram o protagonismo dos profissionais da educação. Entretanto, há que se ter cuidado para que não se sobrecarregue demais tais profissionais, com responsabilidades para além de sua atuação no contexto de uma sociedade melhor, mais digna, mais ética, mais pautada no conhecimento (científico). Delegar a um único profissional a decisão por todas ações, dificultando o diálogo com outros profissionais no interior do seu próprio campo pode ser algo perigoso, perpetuando a forma individualista de se resolver problemas na atualidade, o que, sabemos, não é algo prescritivo e recomendável. Contreras (2012: 145) afirma: "deixar para a exclusiva decisão profissional, justificada em sua necessária autonomia, as decisões educativas, é resolver de modo unilateral o que é plural". 
Ao professor de EF, seja em sua formação, ou em sua atuação, coloca-se nessas duas concepções, do professor-reflexivo e do professor-pesquisador, um diálogo com novas metodologias, sem esquecer-se da discussão, sempre necessária, entre teoria e prática. Àqueles em especial que atuam e pesquisam na EI, os desafios são ainda maiores, por ser um movimento novo no interior do campo, que demandará um trabalho de convencimento, também, da própria equipe pedagógica da escola, que se acostumou a esperar "pouco" daqueles envolvidos com a EF.

Mergulhar no universo das crianças pequenas - da infância em geral - ampliará as possibilidades de descoberta dos professores. Conforme apontou Contreras (2012) ao abordar sobre o professor reflexivo, é preciso entender a dupla necessidade da formação/atuação, qual seja, primeiramente, entender e interpretar a situação que se coloca como problemática no momento, para, depois, modificá-la, elaborando novas atuações como produto de uma nova interpretação. Lembremos, pois, que embora se espere (e haja, até, uma "cobrança") pelo "novo", quando ele ocorre, traz consigo desconfianças, desajustes, insegurança, novas e diferentes discussões.

Conforme Stenhouse, quando citado por Contreras (2012), se o ensino é uma arte, certamente a minúcia de captar esse cotidiano - pela investigação empírica coloca-se também como uma tarefa artística e subjetiva de envolver-se num universo de descobertas outrora escondido, proibido, das singularidades das situações educativas.

Refletir e investigar, investigar e refletir, eis algumas "chaves" que esperamos ter trazido ao debate na tentativa de aprofundar e ampliar as possibilidades de formação, atuação e pesquisa àqueles que se dedicam a pensar a Educação Física, também, na Educação Infantil.

\section{Referências bibliográficas}

Belloni, ML (2001). O que é mídia-educação. Campinas: Autores Associados.

Bracht, V. (1997). Educação Física e aprendizagem social. 2a. Edição. Porto Alegre: Magister.

Charlot, B. (2005). Ensinar, formar: lógica dos discursos constituídos e lógica das práticas. En: Charlot, B. (Ed.). Relação com o saber, formação dos professores e globalização: questões para a educação hoje (pp. 89-99). Porto Alegre: Artmed. 
Chauí, M. (2003). A universidade pública sob nova perspectiva. Revista Brasileira de Educação. 24. Consulta realizada em 26 de março 2014. http://www.scielo.br/scielo.php?script=sci_arttext\&pid=S141324782003000300 $\underline{002 \& \operatorname{lng}=\mathrm{en} \& n r m=\text { iso. }}$.

Contreras, J. (2012). O docente como profissional reflexivo. En: Contreras, J. $A$ autonomia de professores (pp.117-146). $2^{\mathrm{a}}$ ed. São Paulo: Cortez.

Demo, P. (2003). Educar pela pesquisa. 6a. Ed. Campinas: Autores Associados.

Fantin, M. (2006). Mídia-Educação: conceitos, experiências, diálogo Brasil-Itália. Florianópolis: Cidade Futura.

Ferrés, J. (1996). Televisão e educação. Porto Alegre: Artes Médicas.

Mauss, M. (1974) As técnicas do corpo. En: Maus, M. Sociologia e antropologia (pp.399-422). São Paulo: Edusp.

Meksenas, P. (2002). Pesquisa social e ação pedagógica. São Paulo: Loyola.

Oliveira, RC de. (2000). O trabalho do antropólogo: olhar, ouvir, escrever. En: Oliveira, RC de. O trabalho do antropólogo (pp.17-35). Brasília: Paralelo 15; São Paulo: Unesp.

Pinto, FM (2002). A prática de ensino nos cursos de formação de professores de Educação Física. En: Vaz, AF y Sayão, DT y Pinto, FM (Ed). Educação do corpo e formação de professores: reflexões sobre a Prática de Ensino de Educação Física (pp.13-44). Florianópolis: UFSC.

Richter, AC y Vaz, AF. (2005). Corpos, saberes e infância: um inventário para estudos sobre a educação do corpo em ambientes educacionais de 0 a 6 anos. Revista Brasileira de Ciências do Esporte, 26, 3, 79-93.

Rodrigues, AT. (1998). A questão da formação de professores de Educação Física e a concepção de professor enquanto intelectual-reflexivo-transformador. Pensar a Prática, 1.

Sayão, DT. (2002). Corpo e movimento: notas para problematizar algumas questões relacionadas à educação infantil e à educação física. Revista Brasileira de Ciências do Esporte, 23, 2, 55-67. 
Silva, MR. Da y Pires, G De L. (2007). Educação física na educação infantil: retomando projetos e apontado caminhos. Motrivivência, XIX, 29, 07-12.

Vaz, AF. (1994). A pesquisa como prática pedagógica: uma resposta à pergunta “Pesquisa em Educação Física: para quê e para quem?”. Motrivivência, 5, 6 e 7, $60-62$.

- (2008). Sobre a relação ensino-pesquisa na formação inicial em Educação Física. Motrivivência, XX, 30, 76-90.

Vieira, CLN y Welsch, NLN de A. (2007). O lugar da infância e da formação humana na formação inicial em Educação Física. Motrivivência, XIX, 29, 129-140. 